\title{
Energy Conversion Efficiency in Low- and Atmospheric-Pressure Plasma Polymerization Processes with Hydrocarbons
}

\author{
Dirk Hegemann, ${ }^{* a}$ Bernard Nisol, ${ }^{b}$ Sandra Gaiser, ${ }^{a}$ Sean Watson ${ }^{b}$ and Michael R. Wertheimer ${ }^{b}$ \\ Since the earliest days of this field there has been an interest to correlate the structure of plasma polymer (PP) coatings \\ with deposition parameters, most particularly with energy input per monomer molecule, $E_{\mathrm{m}}$. Both of our laboratories have \\ developed methods for measuring $E_{\mathrm{m}}$ (or somewhat equivalent, the apparent activation energy, $E_{\mathrm{a}}$ ) in low- (LP) and \\ atmospheric-pressure (AP) electrical discharge plasmas. We recently proposed a new parameter, energy conversion \\ efficiency (ECE), which for the first time permits direct comparison of LP and AP experiments. Here, we report the case of \\ small hydrocarbons, namely acetylene, ethylene and methane. "Critical" $E_{\mathrm{m}}$ (or $E_{\mathrm{a}}$ ) values that demarcate $E C E$ regimes \\ separating different reaction mechanisms are found to agree remarkably well, and to correlate with specific reaction \\ mechanisms, including dissociation, recombination, gas-phase oligomerization, and surface processes.
}

a Empa, Swiss Federal Laboratories for Materials Science and Technology, Plasma \& Coating Group, Lerchenfeldstrasse 5, 9014 St. Gallen, Switzerland. E-mail: dirk.hegemann@empa.ch

${ }^{b}$ Department of Engineering Physics and Groupe des Couches Minces (GCM), Polytechnique Montréal, Box 6079, Station Centre-Ville, Montreal, QC, H3C 3A7, Canada

\section{Introduction}

This work investigates plasma polymerization (PP) of common hydrocarbon monomers $\left(\mathrm{CH}_{4}, \mathrm{C}_{2} \mathrm{H}_{4}\right.$ and $\left.\mathrm{C}_{2} \mathrm{H}_{2}\right)$ by comparing non-thermal atmospheric-pressure (AP) dielectric barrier discharge (DBD) alternating current / high-voltage (a.c. HV) plasmas with low-pressure (LP) radio-frequency / capacitively-coupled (RF CCP) plasma processes. While the hydrocarbon monomers were highly diluted in Ar for DBD, pure monomer plasmas were examined at LP conditions. Such hydrocarbon discharges are of particular interest for depositing amorphous hydrogenated carbon (a-C:H) films, properties of which can range from soft polymer-like to hard diamond-like coatings, also depending on the hydrogen-to-carbon ratio of the monomer. ${ }^{1-5}$ While dense, hard and smooth a-C:H films are used, for example, as wear resistant, biocompatible and/or barrier coatings (requiring energetic particle bombardment, favored by LP plasma deposition conditions), ${ }^{6-9}$ polymer-like films can be used, for example, for their optical properties, for membrane distillation and diffusion control, for single-step loading with nanoparticles, and they can also be deposited on delicate materials of biological origin, the latter being favored by AP plasma conditions. ${ }^{10-14}$ Moreover, hydrocarbons can also be used as polymerizing agents when mixed with other reactive gases, so as to obtain functionalized plasma polymer films both at LP and AP. ${ }^{15-18}$

Over the last two decades, the use of DBDs for thin film deposition has gained increasing interest, while plasma sources, diagnostics and modeling made significant progress. ${ }^{19-23}$ Because plasma polymerization is initiated by molecular dissociation in the gas phase, the energy per monomer molecule available in the plasma zone is a key parameter - regardless of the particular plasma source being used. ${ }^{24}$ The major importance of this (also called) specific energy input (SEI) has been recently reconfirmed for plasma-chemical hydrocarbon conversion using DBDs, wherein power, gas flow, plasma volume, and temperature have been varied. ${ }^{23,25}$ Based on the calculation of this energy (SEI or $E_{\mathrm{m}}$, see below) in both AP and LP discharges, a previous study had revealed remarkably good agreement between observed threshold energies for $\mathrm{C}_{2} \mathrm{H}_{2}(\sim 9 \mathrm{eV})$ and $\mathrm{C}_{2} \mathrm{H}_{4}$ (12-13.5 eV) related to plasma-chemical reaction pathways, while $\mathrm{CH}_{4}$ manifested a larger discrepancy ( $\sim 11$ vs. $\sim 5 \mathrm{eV}$ ), albeit with some uncertainty. ${ }^{26} \mathrm{~A}$ continuing discussion of apparent activation energies in PP processes is thus undertaken here, picking up the recently-introduced concept of "Energy Conversion Efficiency" (ECE). ${ }^{27-29}$ Therefore, two different energy-related conversion parameters were used as the basis to compare plasma polymerization processes at AP and LP, namely the energy uptake by monomer molecules themselves, $E_{\mathrm{m}}$, and deposition rates, $R_{\mathrm{m}}$.

For calculating energy input per molecule at $\mathrm{AP}, E_{\mathrm{m}}$, energy transfer to the monomer molecules from the inert argon ( $\mathrm{Ar}$ ) carrier gas via excited $\mathrm{Ar}^{*}$ and $\mathrm{Ar}^{+}$species, $\Delta E_{\mathrm{g}}$, per cycle of the applied a.c. HV discharge was determined, as earlier described in detail. ${ }^{26}$ Note that reactions between the highly diluted monomer molecules and the inert Ar carrier gas can be described by a lumped excited $\mathrm{Ar}$ * species akin to the case of electron-impact reactions in the absence of inert gas. ${ }^{22}$ Considering the applied

This document is the accepted manuscript version of the following article: Hegemann, D., Niso1, B., Gaiser, S., Watson, S., \& Wertheimer, M. R. (2019). Energy conversion efficiency in low- and atmospheric-pressure plasma polymerization processes with hydrocarbons. Physical Chemistry Chemical Physics, $21,8698-8708$. 
frequency, $f$, at constant input power, $W$, and the absorbed energy difference (with and without monomer added in the carrier gas), $\Delta E_{g}$, the total energy uptake by monomer molecules, $\Delta E_{g} \cdot f$, was then related to their number entering into the discharge zone, $N_{0}$, which is evidently proportional to the monomer flow rate, $F_{\mathrm{m}}$ :

$$
E_{m}=\frac{\Delta E_{g} f}{N_{0}}
$$

For LP conditions, nominal values for $W$ and $F_{\mathrm{m}}$ can be related to energy uptake per monomer molecule in the plasma zone, $E_{\mathrm{pl}}$, by considering power absorption, plasma expansion and actual gas flow through the reactor. ${ }^{29}$ For well-defined reactor geometries these can all be combined into one proportionality factor, $r_{\mathrm{p} \mid}:{ }^{30}$

$$
E_{p l}=r_{p l} \frac{k T_{0}}{e p_{0}} \frac{W}{F_{m}}
$$

whereby $W / F_{\mathrm{m}}$ in units of $\left[\mathrm{J} \mathrm{cm}^{-3}\right]$ is converted to the unit $[\mathrm{eV}]$ regarding Boltzmann constant, $k$, elementary charge, $e$, temperature, $T_{0}$, and pressure, $p_{0}$, at standard conditions. Hence, both parameters in eq. (1) and (2) are directly linked to the wellknown reaction parameter $W / F_{m}$, the energy input into the plasma zone.

The concept of energy conversion efficiency $(E C E)$ that we introduced some time ago relates an energy-dependent useful output parameter, the conversion, to the externally applied energy input, that is:

$$
E C E_{A P}=\frac{E_{m}}{W / F_{m}}
$$

and

$$
E C E_{L P}=\frac{R_{m} A_{d e p} / F_{m}}{W / F_{m}}
$$

in the AP and LP cases, respectively, the latter using normalized deposition rate (per unit area, $A_{\text {dep, }}$ and monomer flow rate). ${ }^{28}$ Likewise, the conversion can be related to $S E I$ using internally absorbed energy, as is usually done in plasma-based gas conversion. While $E_{\mathrm{m}}$ directly accounts for conversion of monomer into activated film-forming species in the plasma, measurement of the deposited mass, $R_{\mathrm{m}}$, is proportional to the flux of film-forming species arising from monomer conversion. Hence, investigation of $E_{\mathrm{m}}$, deposited mass and $E C E$ that depends on $W / F_{\mathrm{m}}$ enables one to identify PP regimes and activation (threshold) energies. ${ }^{27}$ Note that the concept of energy efficiency, as used for plasma-chemical gas conversion, is to some extent similar in that it considers one specific chemical reaction and the associated total standard enthalpy of formation. ${ }^{31}$ Compared with previously-examined monomers, acrylic acid and HMDSO, the hydrocarbons are "simpler" because they comprise a lesser number of constituent atoms, hence also variety of chemical bonds, but they can still reveal complicating effects, namely many different reaction pathways and recombination in the gas phase, mainly at elevated pressure.5,22,23,32 Therefore, the aim here is to compare $E C E$ for non-thermal PP of hydrocarbons at $\mathrm{LP}$ and $\mathrm{AP}$, in order to experimentally secure information about chemical reaction pathways; this may be understood as a complementary approach to modelling, specifically in regard to uncertainties in cross sections and rate coefficients. ${ }^{33}$

\section{Experimental}

For LP experiments, a symmetric CCP $13.56 \mathrm{MHz}$ (RF) reactor with $30 \mathrm{~cm}$ electrode diameter and $5 \mathrm{~cm}$ gap was used. The hydrocarbon monomers, $\mathrm{CH}_{4}, \mathrm{C}_{2} \mathrm{H}_{4}$, and $\mathrm{C}_{2} \mathrm{H}_{2}$, were fed at a flow rate, $F_{\mathrm{m}}=16 \mathrm{sccm}$ (and also $30 \mathrm{sccm}$ for $\mathrm{CH}_{4}$ ), while varying power input from 5 to $150 \mathrm{~W}$ at fixed pressure, $p=7.5 \mathrm{~Pa}$ (unless otherwise stated). Electrical discharge parameters (excitation voltage, current and phase angle) were recorded using a $\mathrm{V} / \mathrm{I}$ probe (ENI model 1065), and electron densities, $n_{\mathrm{e}}$, were measured by microwave interferometry (JE Plasma Consult MWI 2650). Due to the well-defined plasma volume, $V_{\mathrm{pl}}$, efficient power absorption, $W_{a b s}$, and directed gas flow, internal operating parameters were also well defined as shown in Fig. 1: constant power absorption ( $83 \pm 4 \%$ ), with plasma filling the full chamber, and steadily increasing $n_{\mathrm{e}}$ with rising $W$ (but increasing slightly with rising $p$ ).
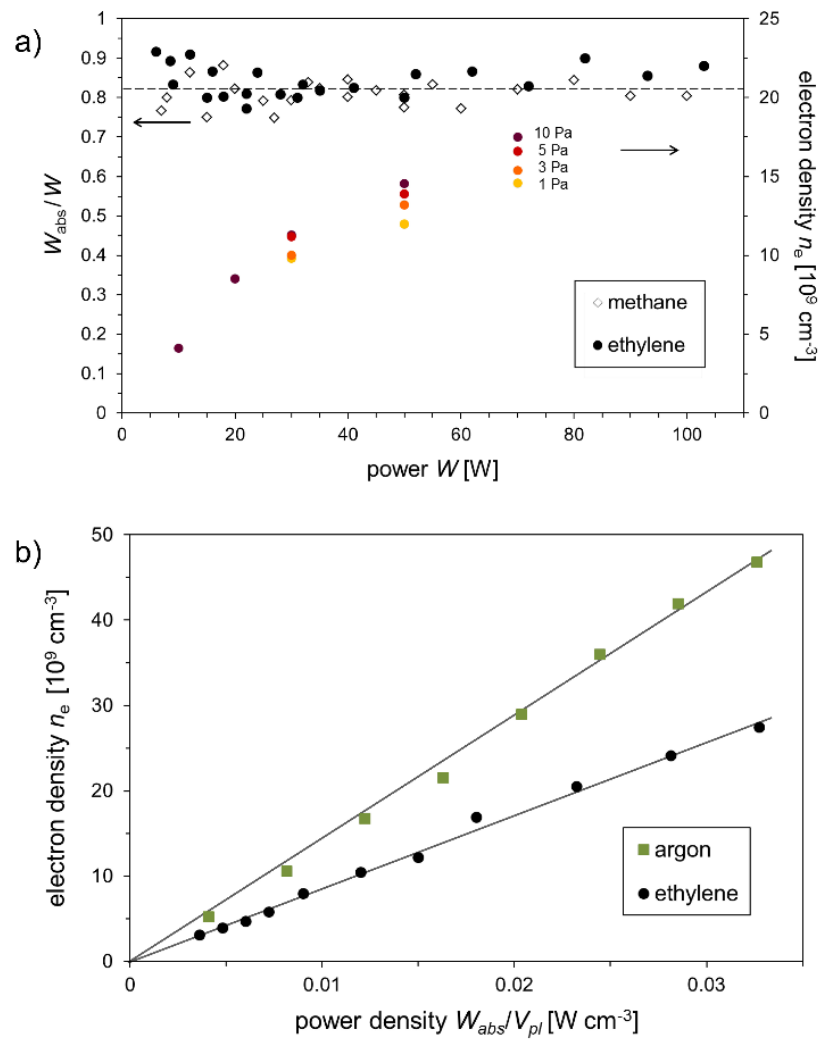

Fig. 1 Measured values of absorbed power, $W_{\text {abs }} / W$ (using the $V / I$ probe; for $\mathrm{CH}_{4}$ and $\mathrm{C}_{2} \mathrm{H}_{4}$ ) and of electron densities, $n_{\mathrm{e}}$ (by $\mathrm{MWI}$; for $\mathrm{C}_{2} \mathrm{H}_{4}$ ) as functions of input power, $W(\mathrm{a})$, and absorbed power density, $W_{\mathrm{abs}} / V_{\mathrm{pl}}$ (b), for selected LP process conditions.

Moreover, $n_{\mathrm{e}}$ was found to increase linearly with the absorbed power density 


$$
n_{e}=\eta_{e} \frac{W_{a b s}}{V_{p l}}
$$

and with the efficiency of power coupling, $\eta_{e}$, whereby hydrocarbon plasmas show lower $n_{\mathrm{e}}$ than Ar due to higher energy losses in inelastic collisions. ${ }^{34}$ Note that $\operatorname{similar} n_{\mathrm{e}}$ values are typically reported for homogeneous DBDs in $\operatorname{Ar}\left(10^{10}\right.$ to $10^{11} \mathrm{~cm}^{-}$ 3). ${ }^{35,36}$

For the well-defined vertical flow in the LP plasma reactor at sufficiently high total gas flow rate, $F_{\mathrm{m}}>10 \mathrm{sccm}$, the proportionality factor in eq. (2) is constant, $r_{\mathrm{pl}}=0.55 .{ }^{30}$ Note that $1 \mathrm{eV}$ per molecule corresponds to $4.3 \mathrm{~J} \mathrm{~cm}^{-3}$. Yet, comparable results were also obtained using different plasma reactors and plasma sources, i.e. different excitation frequencies, which revealed device-independent PP processes in the gas phase. ${ }^{24,28,37}$ Mass deposition rates, normalized to deposition area, $\sim 1700 \mathrm{~cm}^{2}$, and $F_{\mathrm{m}}$ values, were evaluated using a microbalance (Mettler AE200, with $0.1 \mathrm{mg}$ precision) for determining weight gain on glass slide substrates. Film thickness was measured by profilometry (Veeco Dektak 150).

The DBD plasma reactor and its ancillary systems have been earlier described in detail, $26,38,39$ so this needs no repetition here. Briefly, the top and bottom dielectrics, separated by a $2 \mathrm{~mm}$ gap, were respectively Macor $^{\circledR}$ ceramic (3.50 $\pm 0.05 \mathrm{~mm}$ thick) and glass $(3.00 \pm 0.02 \mathrm{~mm})$ plates. The plasma volume was $V_{A P}$ $\approx 43 \mathrm{~cm}^{3}$. All experiments were carried out in DBD plasma sustained by audio-frequency power at constant frequency and applied voltage, $f=20 \mathrm{kHz}, V_{\mathrm{a}}(f)=2.8 \mathrm{kV}, \mathrm{rms}$ ( $=8 \mathrm{kV}$, peak-topeak). Argon (Ar) was used as the inert carrier gas $(99.9+\%$ purity, Air Liquide Canada, Ltd., Montreal), at 10 standard liters per minute $(\mathrm{s} / \mathrm{m})$, controlled by a rotameter-type flowmeter (Matheson, model 7642H, tube 605). Hydrocarbon monomer flows, $F_{\mathrm{m}}$ (in sccm), were controlled with an electronic mass flow meter (MKS, type 1259B, 0-100 sccm) and MKS power supply (model 247B). All were 99+\% purity; they corresponded to concentrations in the \%o range in the $10 \mathrm{slm} \mathrm{Ar}$ carrier gas stream, the monomer being added to the carrier before entering the plasma zone via a gas diffuser. Without repeating details presented earlier, ${ }^{26,39,40}$ measurements of (a) the absorbed energy difference, $\Delta E_{\mathrm{g}}$, and (b) the energy per molecule, $E_{\mathrm{m}}$ (in $\mathrm{eV} /$ molecule) were carried out. This was possible by using the equivalent circuit model and the dedicated MATLAB ${ }^{\circ}$ program for computing $E_{\mathrm{g}}$, energy dissipated in the AP plasma during each applied HV cycle. ${ }^{40}$ These experimental conditions ensured nearly constant power input, $W$, while $F_{\mathrm{m}}$ was varied. This allowed us to cover a comparable range of the $W / F_{m}$ parameter as in LP experiments; therefore, we can plot the abscissae of graphs below, which respectively relate to AP and LP experiments, as $\left[1 / F_{\mathrm{m}}\right]$ and $E_{\mathrm{pl}}\left(\sim W / F_{\mathrm{m}}\right)$, because both $W$ and $F_{\mathrm{m}}$ can vary in the LP case, as already pointed out above.

\section{Results and discussion}

As mentioned above, plasma polymerization (PP) depends on conversion of the monomer gas molecules into film-forming species via gas phase processes, which contribute to film growth that represent surface processes. Starting from a simple rate equation for the production of film-forming species, one can show that monomer conversion directly depends on energy input per monomer molecule, thus on the reaction parameter $W / F_{\mathrm{m}} \cdot{ }^{27,41}$ For low energy input, below the energy required for direct radical formation, where one can assume that the collision frequency for monomer excitation reactions (monomer particle density times averaged reaction rate coefficient) remains constant, which holds true for vibrational excitation, ${ }^{31}$ conversion is expected to increase linearly with rising energy input up to a certain threshold energy. ${ }^{41}$ If one further assumes that the threshold energy, $E_{\mathrm{th}}$, identifies an apparent activation energy or "activation barrier", $E_{\mathrm{a}}$, required to initiate a specific plasma-chemical reaction pathway such as radical formation, an Arrhenius-like relationship (a modified Arrhenius approach, using specific energy input, SEI, instead of temperature) can be considered for ensuing conversion at still-higher energy input (Fig. 2). The maximum energy conversion efficiency, ECE, is thus limited to $\exp (-1)$, i.e. $\sim 0.37$, considering the chemical reaction with its activation barrier $E_{\mathrm{a}}$, as shown by the plateau up to $E_{\mathrm{a}}$ in Fig. 2, which will be discussed further in section 3.4 below. Note that here (as in the following) it is the internally absorbed energy that is used to calculate $E C E$.

The energy input per monomer molecule in the plasma zone, which depends on $W / F_{\mathrm{m}}$, and related threshold energies can now be used to compare PP at different $p$ values, namely LP and $A P$. For the case of HMDSO plasmas at $A P$ and $L P$, we recently showed that $E C E$ curves based on $E_{\mathrm{m}}$ and on deposited mass indeed correlate well. ${ }^{28} \mathrm{Here}$, this same approach is further pursued by comparing acetylene $\left(\mathrm{C}_{2} \mathrm{H}_{2}\right)$, ethylene $\left(\mathrm{C}_{2} \mathrm{H}_{4}\right)$, and methane $\left(\mathrm{CH}_{4}\right)$ discharges, in which reactions proceed mainly by hydrogen abstraction at respective bond energies of 5.7, 4.8 and $4.5 \mathrm{eV}$, whereas dissociation energies for $\mathrm{C} \equiv \mathrm{C}$ and $\mathrm{C}=\mathrm{C}$ bonds require higher respective values, 8.7 and $6.4 \mathrm{eV} .{ }^{42}$

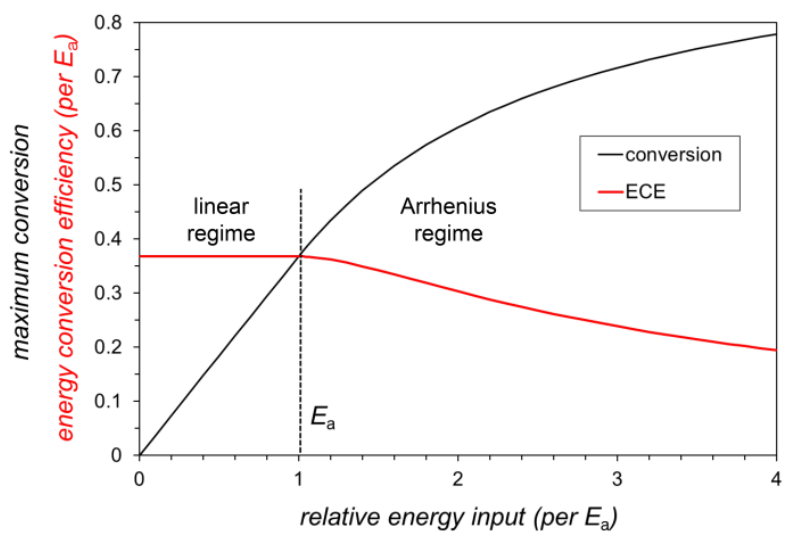

Fig. 2 Basic curves representing (i) maximum conversion and (ii) energy conversion efficiency, assuming Arrhenius-like activation with an "apparent" activation energy, $E_{a}$, which separates the linear and the Arrhenius regime as marked by the dashed line. Note that horizontal and vertical axes show normalized (not experimental) values indicating a theoretical maximum ECE of $\sim 37 \%$ (see also discussion in section 3.4 ).

\subsection{Acetylene}

PP of $\mathrm{C}_{2} \mathrm{H}_{2}$ at AP and LP has already been compared and discussed to some extent: 27 in both cases a linear increase in $R_{\mathrm{m}}$ 
(LP) and $E_{\mathrm{m}}(\mathrm{AP})$ was observed with rising energy input into the plasma, up to a threshold energy near $9 \mathrm{eV}$ (Fig. 3).

$E C E$ plots thus display near-constant values up to $E_{\mathrm{a}}$, decreasing above that value as shown in Fig. 4. Note that the uncertainty becomes higher for ECE values at low energy input. A linear increase in deposition rate up to a threshold value was also reported by Cheng et al. in $\mathrm{C}_{2} \mathrm{H}_{2}(+\mathrm{Ar})$ discharges at LP (10 Pa), as power input was increased at fixed gas flow rates. ${ }^{43}$ In Fig. 3a, starting at $E_{\mathrm{a}}$, the deposition rate follows Arrhenius-like behavior that would confirm production of film-forming species governed by plasma-chemical reactions in presence of an activation barrier. Electron-impact dissociation channels for $\mathrm{C}_{2} \mathrm{H}_{2}$ were reported to proceed above threshold energies of 7.5-11.4 eV (average value of $8.7 \mathrm{eV}$, considering the cross section branching ratios for each channel), predominantly by hydrogen abstraction that yields $\mathrm{C}_{2} \mathrm{H} \bullet$ and $\mathrm{C}_{2} \bullet$ radicals; ${ }^{44}$ this agrees well with the observed $E_{\mathrm{a}}$ value.
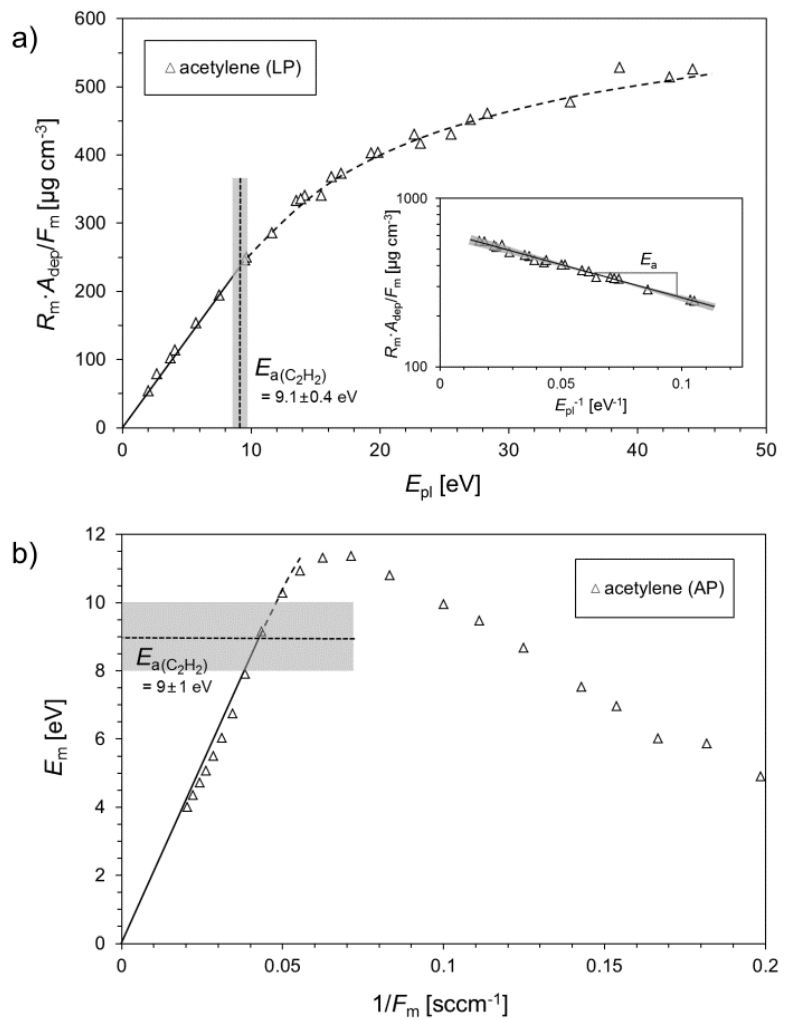

Fig. 3 Dependence of deposited mass, $\left.R_{\mathrm{m}}(\mathrm{LP}, \mathrm{a})\right)$ and energy input per $\mathrm{C}_{2} \mathrm{H}_{2}$ molecule, $\left.E_{\mathrm{m}}(\mathrm{AP}, \mathrm{b})\right)$ on energy input into the plasma, $E_{\mathrm{pl}}$ and $F_{\mathrm{m}}{ }^{-1}$, respectively. Linear increases (solid line fits) are observed up to threshold energy of ca. $9 \mathrm{eV}$ (shaded lines). Above $E_{\mathrm{a}}$, the Arrhenius regime is indicated by dashed lines. The insert in a) shows the Arrheniuslike plot for determining $E_{\mathrm{a}}$. Corresponding uncertainty ranges are indicated by grey areas.

At AP, $\mathrm{C}_{2} \mathrm{H}_{2}$ dissociation proceeds largely via energy transfer from $\mathrm{Ar}^{*}$ (henceforth, this is meant to include $\mathrm{Ar}_{2}{ }^{*}$ ) and $\mathrm{Ar}^{+} \mathrm{ra}-$ ther than by direct electron impact, yielding $\mathrm{C}_{2} \mathrm{H}_{2}{ }^{+}$as an intermediary state, followed by $\mathrm{C}_{2} \mathrm{H} \bullet, \mathrm{C}_{2} \bullet$ and $\mathrm{CH} \bullet$ formation. ${ }^{5}$ Nonetheless, the observed threshold energy is comparable to that at $\mathrm{LP}$, even though the $E_{\mathrm{m}}$ data are seen to deviate slightly from "ideal" linear fit. Remembering that $E_{\mathrm{m}}$ is based on the number of $\mathrm{C}_{2} \mathrm{H}_{2}$ molecules entering into the discharge zone (see eq. (1)), their actual number, $N$, might however differ because dissociation increases $N$, while recombination, plasma-phase oligomerization and surface losses decrease its value. In the latter case, the energy dissipation over one discharge cycle is shared by a smaller number of precursors along their pathway through the discharge zone; as a result, $E_{\mathrm{m}}$ based on $N_{0}$ becomes underestimated. Therefore, it can be assumed for energies below $E_{\mathrm{a}}$, that is at high $F_{\mathrm{m}}$, (i) that a small number of $\mathrm{CH} \bullet$ radicals from dissociation recombine with $\mathrm{C}_{2} \mathrm{H}_{2}$, and (ii) that plasma-phase oligomerization becomes important, clearly manifested by powder formation, thereby reducing $N$. Recombination of $\mathrm{CH} \bullet$ radicals with other molecules in $\mathrm{C}_{2} \mathrm{H}_{2}$ plasma has been confirmed by Poncin-Epaillard et al. when $F_{\mathrm{m}}$ and $p$ were high. ${ }^{45}$
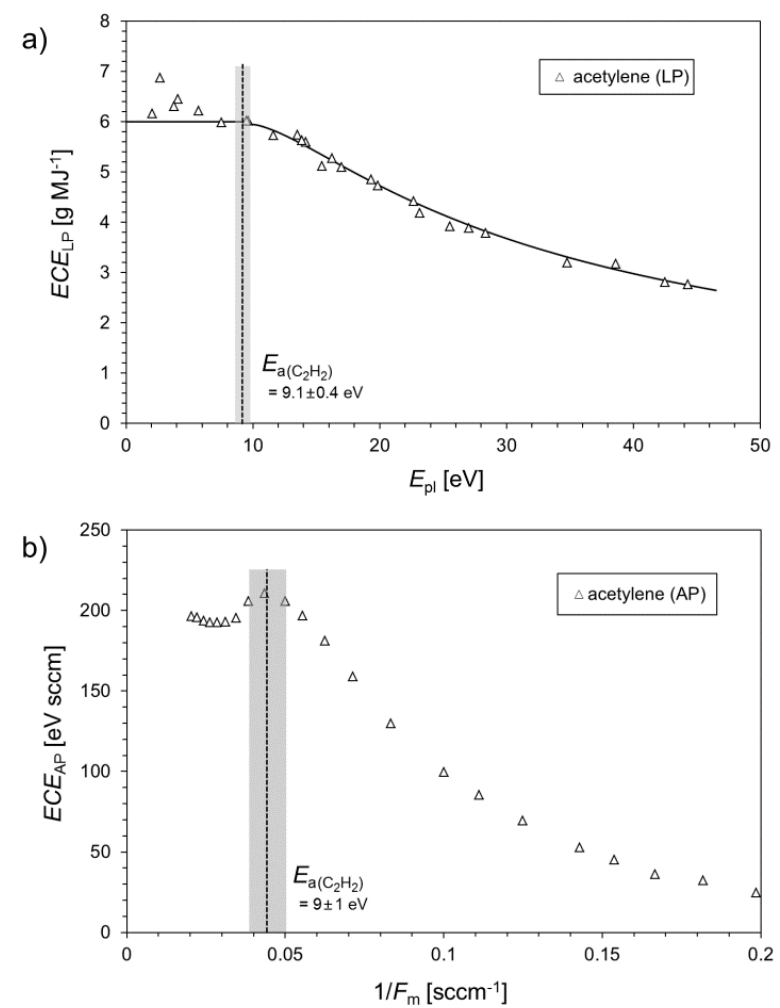

Fig. 4 Plots of Energy Conversion Efficiency (ECE) derived from deposited mass (LP, a)) with corresponding fit of the linear and Arrhenius regime (solid line) and from energy input per $\mathrm{C}_{2} \mathrm{H}_{2}$ molecule $(A P, b)$ ), both versus energy input into the plasma. The threshold energy of ca. $9 \mathrm{eV}$ is marked by the shaded lines, with indicated uncertainty range.

With decreasing $F_{\mathrm{m}}$, corresponding to higher $E_{\mathrm{m}}$ at fixed power input, on the other hand, $\mathrm{H}$ abstraction and $\mathrm{C}_{2} \mathrm{H} \bullet$ species were found to dominate, in agreement with the a-C:H deposition model in $\mathrm{Ar} / \mathrm{C}_{2} \mathrm{H}_{2}$ plasma of Gielen et al. ${ }^{46}$ Recombination becomes less likely, while highly reactive $\mathrm{C}_{2} \mathrm{H} \bullet$ radicals lead to higher losses via film deposition, the sticking probability, $s$, of $\mathrm{C}_{2} \mathrm{H} \bullet$ having been reported as high as $0.8 .{ }^{47}$ Greatly reduced $N$ in the plasma was therefore presumably responsible for the observed drop in $E_{\mathrm{m}}$ in Fig. $3 \mathrm{~b}$ for energies $>E_{\mathrm{a}}$, while the measured deposition rates in Fig. 3a followed Arrhenius-like behavior. Nevertheless, LP and AP PP of $\mathrm{C}_{2} \mathrm{H}_{2}$ showed strong resemblances, in agreement with conclusions by Heyse et al. ${ }^{11}$ 


\subsection{Ethylene}

Compared to $\mathrm{C}_{2} \mathrm{H}_{2}$, PP of $\mathrm{C}_{2} \mathrm{H}_{4}$ showed somewhat reduced deposition rates but also less powder formation, indicating a lower reactivity both at LP and AP. ${ }^{11,24}$ For both of these hydrocarbons, it might be expected that PP proceeds predominantly via hydrogen abstraction; this was indeed found to be the main dissociative excitation channel by electron-impact, with threshold energies of about 6-8 eV. ${ }^{44} \mathrm{C}=\mathrm{C}$ dissociation requires only slightly higher energies, $8-9 \mathrm{eV}$, and it contributes about $20 \%$ to the reaction channel. Furthermore, $\mathrm{C}_{2} \mathrm{H}_{3} \bullet$ radicals possess lower $s$ values than $\mathrm{C}_{2} \mathrm{H} \bullet(s=0.25$ vs. 0.8$) .{ }^{47}$ It can therefore be assumed that the plasma-chemical reaction pathway for $\mathrm{C}_{2} \mathrm{H}_{4}$ is more complex than that of $\mathrm{C}_{2} \mathrm{H}_{2}$, involving different PP activation reactions. Accordingly, a higher apparent activation energy of $12.3 \pm 0.6 \mathrm{eV}$ was obtained for deposition in $\mathrm{LP} \mathrm{C}_{2} \mathrm{H}_{4}$ plasma (Fig. 5a). Just as observed for the case of $\mathrm{C}_{2} \mathrm{H}_{2}$, the deposited mass increased linearly with rising energy input up to $E_{a}$, followed by the Arrhenius regime at higher energies, which has been used to derive $E_{\mathrm{a}}$ and its corresponding uncertainty range. Evolution of the energy input per $\mathrm{C}_{2} \mathrm{H}_{4}$ molecule, $E_{\mathrm{m}}$, in AP plasma shows similar behavior, as witnessed by Fig. $5 \mathrm{~b}$, where an initial linear increase can be observed up to $\sim 7 \mathrm{eV}$, the value expected for hydrogen abstraction. This is then followed by a steeper rise in $E_{\mathrm{m}}$ up to $E_{\mathrm{a}} \approx 13.5 \pm 2.5 \mathrm{eV}$, the threshold energy derived from Ar* energy transfer with a corresponding uncertainty of $20 \% .{ }^{26}$ Thus, a transition in plasma-chemical reaction pathway appears to lead to the one that favors film deposition - akin to the LP case. Note that a superposition of several Arrhenius regimes for various film-forming species with different activation barriers results in a single overall Arrhenius-like plot with an averaged activation energy. ${ }^{48}$ Similar to the discussion for the $\mathrm{C}_{2} \mathrm{H}_{2}$ case, however, the actual number of molecules in the plasma zone might affect the shape of the recorded $E_{\mathrm{m}}$ curve, due to dissociation, recombination, gas phase oligomerization reactions and to surface losses, the latter mainly at higher energies.

Lefkowitz et al. reported results for DBD-type $\mathrm{Ar} / \mathrm{C}_{2} \mathrm{H}_{4}$ plasmas at $8 \mathrm{kPa}$ (60 torr), ${ }^{49}$ where dissociation of $\mathrm{C}_{2} \mathrm{H}_{4}$ was thought to proceed mainly by hydrogen abstraction via $\mathrm{Ar}^{*}$ and $\mathrm{Ar}^{+}$collisions. The plasma was thus found to be dominated by $\mathrm{C}_{2} \mathrm{H}_{\mathrm{x}} \bullet$ species, the amount of $\mathrm{CH}_{\times} \bullet$ being low, but significant formation of $\mathrm{C}_{3} \mathrm{H}_{6}$ and $\mathrm{C}_{4} \mathrm{H}_{8}$ was also reported. Hence, recombination reactions cannot be ignored for AP PP of $\mathrm{C}_{2} \mathrm{H}_{4}$. Regarding $\mathrm{C}_{2} \mathrm{H}_{x} \bullet$, the formation of $\mathrm{C}_{2} \mathrm{H}_{2}(x=2)$ was found to increase linearly with rising $F_{\mathrm{m}}^{-1}$ (or $W / F_{\mathrm{m}}$ ) within the examined low energy range (up to $5 \%$ conversion), agreeing with the linear increase of $E_{\mathrm{m}}$ up to $\sim 7 \mathrm{eV}$. Consequently, the absolute number of species formed is near-constant in the initial part of the PP regime (where only $F_{\mathrm{m}}$ is varied, $W$ being fixed) - corresponding to nearly constant $E C E$ at low $F_{\mathrm{m}}{ }^{-1}$ up to $E_{\text {a }}^{\prime}$ (Fig. 6). Recombination and oligomerization reactions are most likely to occur in the transition regime near $13.5 \mathrm{eV}$; here, the concomitant reduction in $N_{0}$ and its effect on calculating $E_{\mathrm{m}}$ tends to complicate direct comparison with the LP case, while at high energy input surface losses became dominant, as in the case of $\mathrm{C}_{2} \mathrm{H}_{2}$.
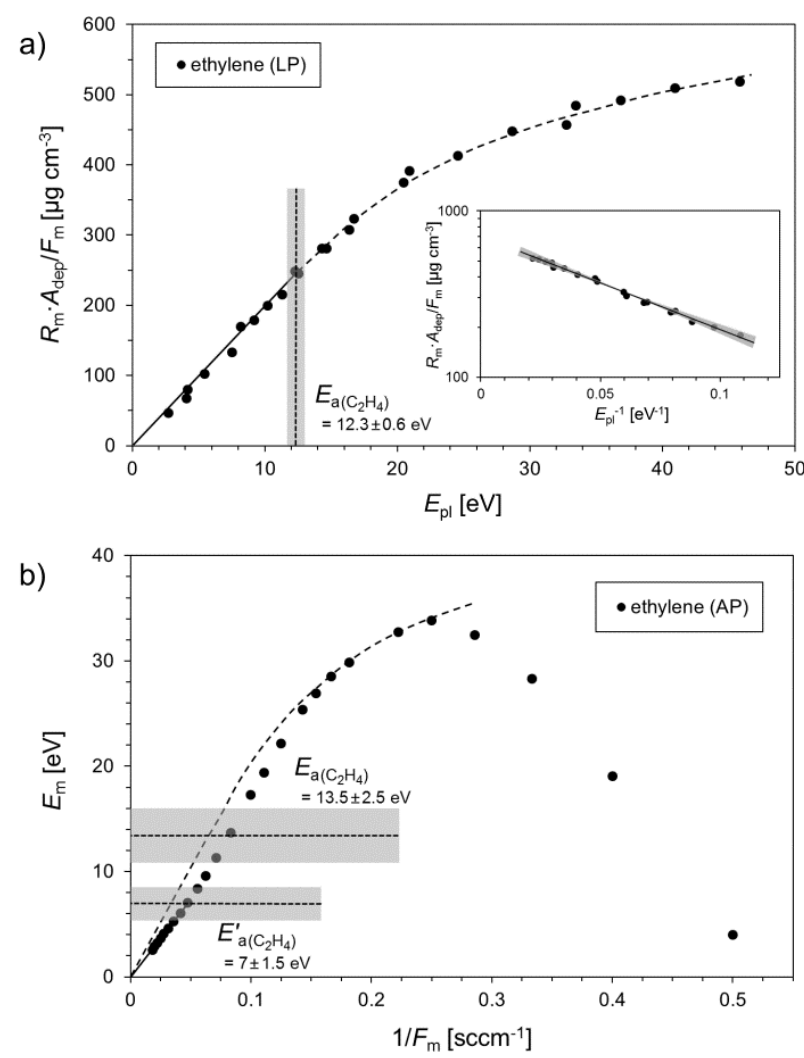

Fig. 5 Plot of deposited mass (LP, a)) and energy input per $\mathrm{C}_{2} \mathrm{H}_{4}$ molecule, $\left.E_{m}(A P, b)\right)$ versus energy input into the plasma. Linear increases (solid line fits) can be observed up to certain threshold energies identified by shaded lines. Above $E_{\mathrm{a}}$, the Arrhenius regime is shown by dashed lines. The insert in a) is the Arrhenius-like plot for the normalized deposition rates. Uncertainty ranges (grey areas) were determined the same way as for $\mathrm{C}_{2} \mathrm{H}_{2}$.

\subsection{Methane}

$\mathrm{CH}_{4}$, the simplest, most abundant hydrocarbon gas is used for plasma depositing wear-protective coatings and for functionalizing contact lenses, to name but two applications. ${ }^{1,4,50}$ Furthermore, plasma-chemical conversion of $\mathrm{CH}_{4}$ to higher hydrocarbons and its dry reforming with carbon dioxide are of great economic interest. ${ }^{31,51,52} \mathrm{PP}$ of $\mathrm{CH}_{4}$ proceeds via hydrogen abstraction, which requires a rather high threshold energy, 8-9 $\mathrm{eV}$, considering the average $\mathrm{C}-\mathrm{H}$ bond energy of $4.5 \mathrm{eV} .{ }^{53}$ Vibrationally-excited $\mathrm{CH}_{4}$ * molecules with threshold energies of 0.16 $\mathrm{eV}$ and $0.37 \mathrm{eV}$ are the most abundant species at low energy input. ${ }^{31,54}$ Since $\mathrm{CH}_{3} \bullet$ and $\mathrm{CH}_{2} \bullet$ radicals have low sticking coefficients, $s<0.025,47$ and the thus likely film-forming species, $\mathrm{CH} \bullet$, contain only a single carbon atom, $R_{\mathrm{m}}$ values are lower than in $\mathrm{C}_{2} \mathrm{H}_{2}$ and $\mathrm{C}_{2} \mathrm{H}_{4}$ plasmas. ${ }^{24,41}$ Therefore, LP experiments were performed not only at $F_{\mathrm{m}}=16 \mathrm{sccm}$, but also at a higher $F_{\mathrm{m}}=30$ sccm, in order to increase $R_{\mathrm{m}}$, particularly at lower energy inputs. 

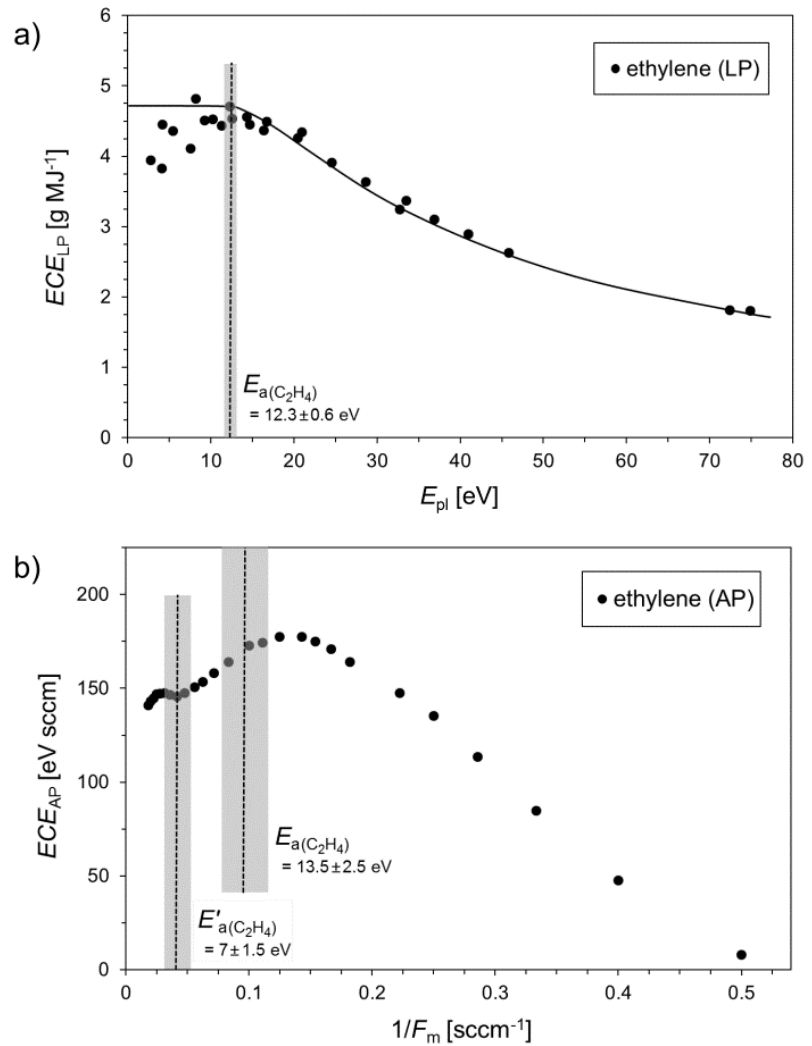

Fig. 6 Plots of Energy Conversion Efficiency (ECE) derived from deposited mass (LP, a)) with corresponding fit of the linear and Arrhenius regime (solid line) and from energy input per $\mathrm{C}_{2} \mathrm{H}_{4}$ molecule $(A P, b)$ ) versus energy input into the plasma. Grey areas identify the uncertainty ranges for the indicated threshold energies.

Fig. 7a shows linear increases in the deposited mass up to a threshold energy of $8.4 \pm 1.5 \mathrm{eV}$, derived via the modified Arrhenius approach. The slopes of the linear fits at both $F_{\mathrm{m}}$ agree quite well, albeit with somewhat larger uncertainty, 18\%, compared with $\mathrm{C}_{2} \mathrm{H}_{2}$ and $\mathrm{C}_{2} \mathrm{H}_{4}$, likely on account of more data scatter). Slightly higher $R_{\mathrm{m}}$, normalized with respect to $A_{\text {dep }}$ and $F_{\mathrm{m}}$, at $F_{\mathrm{m}}=16 \mathrm{sccm}$ are likely due to a longer residence time of the film-forming species at the surface, $A_{\text {dep }}$, and correspondingly smaller re-emission. ${ }^{55}$ However, the small differences $R_{\mathrm{m}}$ indicate that film-forming species might possess an $s$ value near 1 , otherwise reduced residence times at the surface would lead to much smaller $R_{\mathrm{m}}$. This agrees well with findings by Bauer et al., who identified $\mathrm{CH} \bullet$ radicals with an assumed sticking coefficient of $\sim 1$ as the most likely film-forming species in $\mathrm{LP} \mathrm{CH}_{4}$ plasmas. ${ }^{47}$ $\mathrm{CH} \bullet$ radicals are mainly formed by direct impact dissociation involving vibrationally excited $\mathrm{CH}_{4}{ }^{*}$, by dissociative recombination of $\mathrm{CH}_{3}{ }^{+}$, and by the reaction $\mathrm{CH}_{2} \bullet+\mathrm{H} \rightarrow \mathrm{CH} \bullet+\mathrm{H}_{2} .{ }^{56}$

Linear increase in $R_{\mathrm{m}}$ at low energy input correlates well with conversion of $\mathrm{CH}_{4}$ when the parent gas concentration is still high under flow conditions and dissociation results from vibrational excitation. ${ }^{31,57,58}$ Above $E_{\mathrm{a}}, R_{\mathrm{m}}$ values follow the modified Arrhenius approach. As discussed earlier, this allows a maximum ECE of $\sim 37 \%$ for "ideal" energy coupling (see plateau in Fig. 8a). Interestingly, a maximum of $\sim 38 \%$ energy efficiency was reported for $\mathrm{CH}_{4}$ conversion at $\mathrm{p} \approx 10-12 \mathrm{kPa}$, close to that maximum un- der non-equilibrium conditions, while thermal effects are required for higher efficiencies approaching thermodynamic equilibrium conditions. ${ }^{31,59}$ In a hot microwave plasma, for example, methane decomposition was found to start at $1000 \mathrm{~K}$ with the breaking of the $\mathrm{C}-\mathrm{H}$ bond. ${ }^{60} \mathrm{~A}$ modified Arrhenius behavior has also recently been reported for reactions of activated $\mathrm{CH}_{4}{ }^{*}$ at catalyst surfaces in a DBD. ${ }^{25}$
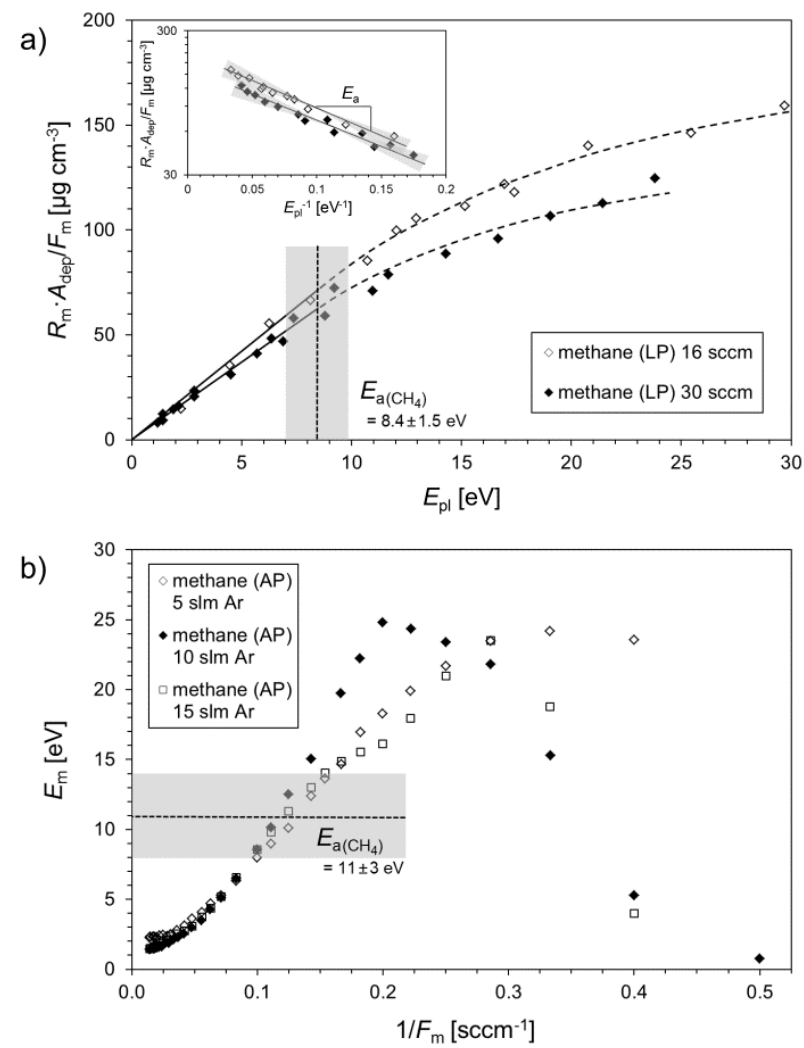

Fig. 7 Plots of deposited mass ( $L P, a)$ ) and of energy input per $\mathrm{CH}_{4}$ molecule, $\left.E_{m}(\mathrm{AP}, \mathrm{b})\right)$, versus energy input into the plasma. The insert in a) shows the Arrhenius-like plot for determining $E_{\mathrm{a}}$ at two different gas flow rates, $F_{\mathrm{m}}$. Solid line fits are observed up to threshold energies marked by the shaded lines. Above $E_{\mathrm{a}}$, the Arrhenius regimes correspond to the dashed lines. Uncertainty areas were determined the same way as for $\mathrm{C}_{2} \mathrm{H}_{2}$.

The slightly lower $E_{\mathrm{a}}$ value we reported earlier for PP of $\mathrm{CH}_{4}{ }^{24,41}$ can now be attributed to an LP reactor with less well-defined plasma volume and other associated experimental conditions. The threshold energy we report here agrees well with electron impact-initiated formation of $\mathrm{CH}_{3} \bullet, \mathrm{CH}_{2} \bullet$ and $\mathrm{CH} \bullet$ radicals (>8 $\mathrm{eV}$ ), in the order of decreasing densities), ${ }^{31,53}$ and it is also comparable to the corresponding AP DBD value, $11 \pm 3 \mathrm{eV} .{ }^{26} \mathrm{How}$ ever, the measured dependence of $E_{\mathrm{m}}$ on energy input, $\propto F_{\mathrm{m}}{ }^{-1}$, appears more complicated (Fig. 7b). Regardless of the Ar carrier gas flow rate $(5,10$ or $15 \mathrm{slm}), E_{\mathrm{m}}$ was seen not to increase linearly, even at the lowest input energy, in stark contrast with the cases of $\mathrm{C}_{2} \mathrm{H}_{2}$ and $\mathrm{C}_{2} \mathrm{H}_{4}$. This finding also differs from the recently reported linear increase in $\mathrm{CH}_{4}$ conversion with rising energy input in DBD reactors, which agrees with the LP case. ${ }^{23,61}$ Moreover, Snoecks et al. reported modelling data (OD kinetic model, Global_kin) for dry reforming of $50-50 \mathrm{CH}_{4}-\mathrm{CO}_{2}$ mixtures in a 
DBD reactor, indicating a nearly linear increase in $\mathrm{CH}_{4}$ and overall gas conversion with rising $S E I$ up to about 4-8 eV $(18-36 \mathrm{~J} \mathrm{~cm}$ $\left.{ }^{3}\right) .{ }^{52} \mathrm{~A}$ plausible explanation for the non-linear increase in Fig. $7 \mathrm{~b}$ may be the following:

The concentration of $\mathrm{CH}_{3} \bullet$ radicals in the plasma, $\left[\mathrm{CH}_{3}\right]$, is governed by their creation via electron impact and Penning transfer to $\mathrm{CH}_{4}$, on one hand, and by recombination and surface losses, on the other. On account of the small $s$ value of $\mathrm{CH}_{3} \bullet$, gas phase recombination tends to dominate over the latter at low energy input (in the order $\mathrm{CH}_{4}>\mathrm{C}_{2} \mathrm{H}_{4}>\mathrm{C}_{2} \mathrm{H}_{2}$ ). This is further favored by the greater mobility of light $\mathrm{CH}_{x} \bullet$ compared with heavier $\mathrm{C}_{2} \mathrm{H}_{\mathrm{y}} \bullet$ species, which results in more collisions in the discharge zone, hence more recombination reactions. ${ }^{62}$ The outcome is dominating recombination to form $\mathrm{C}_{2} \mathrm{H}_{6}, 5,63$ which in turn reduces molecular density in the discharge zone and leads to miscalculation of $E_{\mathrm{m}}$ per $\mathrm{CH}_{4}$ molecule. Substantial recombination of $\mathrm{CH}_{3} \bullet$ to form $\mathrm{C}_{2} \mathrm{H}_{6}$ was also reported by modelling of DBD assisted dry reforming of methane (CHEMKIN-PRO software). ${ }^{64}$ Though, dissociation of $\mathrm{CH}_{4}$ mainly into $\mathrm{CH}_{3} \bullet$ and $\mathrm{H} \bullet$, recombination of $\mathrm{CH}_{3} \bullet$ and $\mathrm{H} \bullet$ back to $\mathrm{CH}_{4}$, as well as the production of $\mathrm{C}_{2} \mathrm{H}_{6}$ via three-body recombination of $\mathrm{CH}_{3} \bullet$ were identified as the most important sources of uncertainty in modelling of $\mathrm{CH}_{4}$ conversion. ${ }^{33}$ Fig. 8 shows a pronounced dip in $E C E_{\mathrm{AP}}$ at intermediate energy input, quite different from $E C E_{\mathrm{LP}}$, believed to result from this proposed recombination scenario. $\left[\mathrm{CH}_{3}\right]$ in $\mathrm{CH}_{4}$ discharges and corresponding recombination was reported to be relatively little affected by $\mathrm{Ar}$ admixture, 65 but residence time in the discharge zone is of course inversely proportional to the total gas flow rate, $F$. In other words, longer residence for the $F=5 \mathrm{slm}$ case reduced surface losses, as noted at higher $F_{\mathrm{m}}$ 1; however, $E C E_{\mathrm{AP}}$ versus ${F_{\mathrm{m}}}^{-1}$ plots are seen to differ only slightly for $F=5,10$, and $15 \mathrm{slm}$ (Fig. 8b). PP of $\mathrm{CH}_{4}$ might be initiated in a similar way for LP and AP, but might proceed differently on account of different recombination reactions and subsequent reaction pathways that depend on residence time in the plasma. This agrees with the kinetics of plasma chemical reactions for AP Ar/ $\mathrm{CH}_{4}$ in the literature, which indicate that filmforming species preferentially originate from $\mathrm{C}_{2} \mathrm{H}_{6}$ than via $\mathrm{CH}_{3} \bullet .^{5}$ Different PP mechanisms have also been proposed, based on comparing LP results for $\mathrm{CH}_{4}$ and $\mathrm{C}_{2} \mathrm{H}_{6} \cdot{ }^{41}$

Indeed, $\mathrm{PP}$ of ethane $\left(\mathrm{C}_{2} \mathrm{H}_{6}\right)$, the next alkane after methane, was found to show two distinct $P P$ regimes that occurred both at LP and $A P .{ }^{27}$ Its bond dissociation energies for $\mathrm{C}-\mathrm{C}$ and $\mathrm{C}-\mathrm{H}$ are respectively 3.6 and $4.4 \mathrm{eV}$; the most likely reaction, $\mathrm{H}_{2}$ abstraction and $\mathrm{C}_{2} \mathrm{H}_{4}$ formation, already proceeds at $\sim 4 \mathrm{eV}$ followed by further $\mathrm{H}_{2}$ abstraction yielding $\mathrm{C}_{2} \mathrm{H}_{2} \cdot{ }^{5,44}$ With increasing energy input, $\mathrm{C}-\mathrm{C}$ dissociation with a threshold of 6-7 eV becomes more likely, yielding additional reaction pathways that result in $\mathrm{CH} \bullet$ and $\mathrm{C}_{2} \mathrm{H} \bullet$ film-forming species. ${ }^{5}$ Nevertheless, these manifest excellent agreement between the AP and LP cases, as we had discussed earlier. ${ }^{27}$

\subsection{Electron conversion efficiency and energy balance}

For plasma comprising a single gaseous molecular specie, the energy absorbed by the electrons per unit volume and unit time is approximately given by: a)
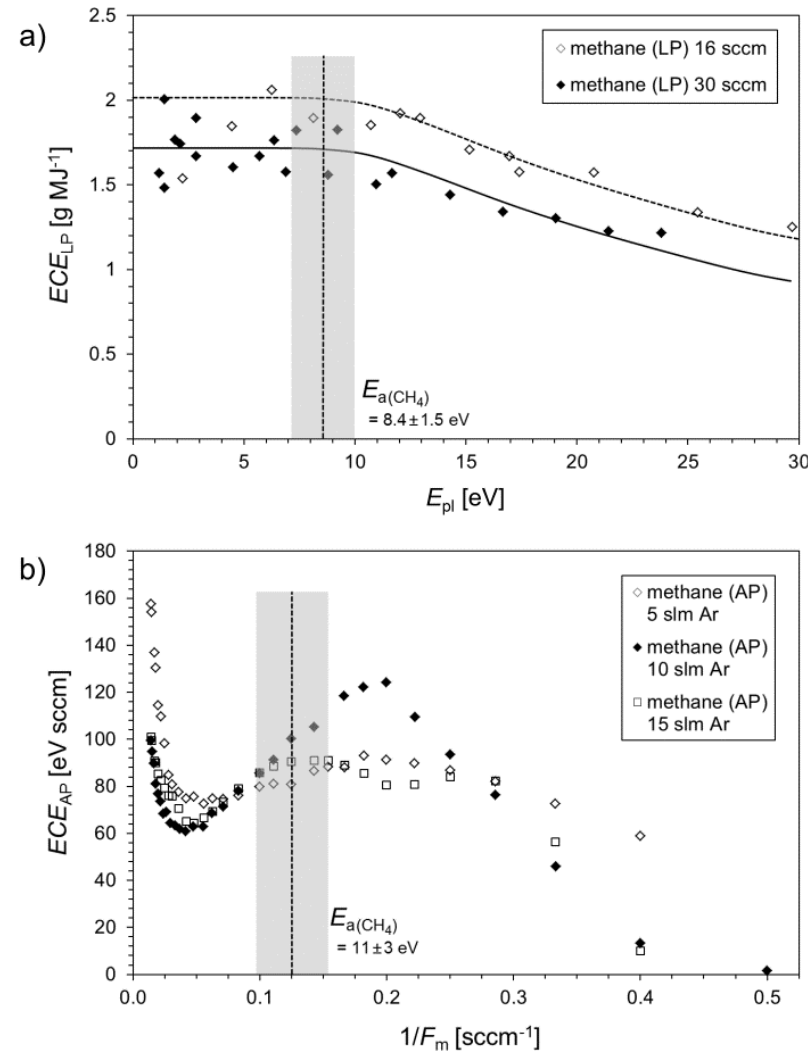

Fig. 8 Plots of Energy Conversion Efficiency (ECE) derived from deposited mass (LP, a)), with corresponding fit of the linear and Arrhenius regime, and from $\left.E_{m}(A P, b)\right)$, versus energy input into the plasma. The dip in (b) is attributed to recombination reactions (see text). Grey areas indicate uncertainty ranges of the particular threshold energies.

$$
P_{a b s}=n_{e} N_{0} \sum_{m} k_{m} E_{m}
$$

where monomer molecule density is $N_{0}$, and there exist different possible excitation mechanisms with rate coefficients, $k_{\mathrm{m}}$, and energies, $E_{\mathrm{m}}{ }^{66}$ Vibrational excitation thus dominates the energy balance, beside the possibility of dissociation at the discussed threshold energies.

The dimensionless $E C E$, converted energy per unit of energy input, can then be written as

$$
E C E=\frac{P_{a b s} \frac{\tau}{N_{0}}}{E_{p l}}=\frac{n_{e} \tau \sum_{m} k_{m} E_{m}}{E_{p l}}
$$

using the confinement time, $\tau$, and the average energy per monomer molecule, $E_{\mathrm{pl}}$. Considering eq. (5) and the fact that

$$
\tau=N_{0} \frac{V_{p l}}{F_{m}} \frac{k T_{0}}{p_{0}}
$$

it follows:

$$
E C E=\frac{\eta_{e} \frac{W_{a b s}}{F_{m}} \frac{k T_{0}}{p_{0}} N_{0} \sum_{m} k_{m} E_{m}}{E_{p l}}
$$

The energy conversion, as presented in eq. (9), thus couples the available energy per monomer in the plasma, via the externally 
applied $W / F_{m}$, to various excitation channels given by their rate coefficients. For energies, $E_{\mathrm{pl}}$, below an activation barrier, $E_{\mathrm{a}}$, (e.g. the threshold energy for dissociation, $E_{\mathrm{th}}$ ), it can be assumed that the sum of excitation rate coefficients is close to the rate coefficient for this activation reaction, $k_{\mathrm{a} .}{ }^{66} \mathrm{Eq}$. (9) can thus be simplified as follows:

$$
E C E \approx \frac{\eta_{e} E_{p l} N_{0} k_{a} E_{a}}{E_{p l}}=\eta_{e} v_{a} E_{a}
$$

with the collision frequency, $v_{\mathrm{a}}\left(=N_{0} k_{\mathrm{a}}\right)$, for activating plasma polymerization reactions. Consequently, one may expect a constant $E C E$ regime with constant $v_{\mathrm{a}}$ for $E_{\mathrm{pl}} \leq E_{\mathrm{a}}$, as experimentally observed, because $\eta_{\mathrm{e}}$ and $T_{\mathrm{e}}$ remain unchanged.

With increasing energy input, $E_{\mathrm{pl}}>E_{\mathrm{a}}$, further reaction channels become available, thereby decreasing $v_{a}$. Therefore, a modified Arrhenius approach has been introduced in the LP case in order to fit the experimental data:

$$
E C E \approx \eta_{e} v_{a} E_{a}=c_{0} \frac{E_{a}}{E_{p l}} \exp \left(-\frac{E_{a}}{E_{p l}}\right)
$$

For $E_{\mathrm{pl}}=E_{\mathrm{a}}$, it thus follows that the maximum $E C E$ reaches $37 \%$ of the maximum conversion, $c_{0}(\leq 1)$, in non-thermal plasmabased monomer conversion.

At AP in homogeneous DBD Ar plasma, $n_{\mathrm{e}}$ may be comparable to $L P, 10^{10}$ to $10^{11} \mathrm{~cm}^{-3}, 35,36$ while $T_{\mathrm{e}}$ is lower, around $0.5 \mathrm{eV}$ compared to around $2.5 \mathrm{eV}$ at $10 \mathrm{~Pa} .^{30,34,67,68}$ The drop in $T_{\mathrm{e}}$, however, is accompanied by enhanced density of Ar metastable states (Ar 1s), underlining the importance of energy transfer through $\mathrm{Ar} *{ }^{68} \mathrm{~A}$ small addition of molecular gas to $\mathrm{Ar}$, however, results in a noticeable drop in $n_{\mathrm{e}} \cdot{ }^{34}$ Likewise, the combined excited $\mathrm{Ar}^{*}$ species density is reduced. ${ }^{22}$ Transferred energy, $\Delta E_{g}$, and absorbed power, $W_{\text {abs, }}$, however, have been found to saturate for an energy input around $E_{\mathrm{a}}$, corresponding to monomer addition $1 / F_{\mathrm{m}}{ }^{26}$ Eq. (10), which considers an average reaction rate coefficient for plasma polymerization might thus still apply. Hence, initial processes leading to plasma polymerization were found to be comparable in the AP and LP cases, but with differences in the overall reaction pathways, because monomer molecules have many more possibilities at elevated pressure for undergoing further inelastic collisions after initial activation.

\subsection{Surface processes}

While PP initiation appears to proceed in comparable ways in LP CCP and AP DBD plasmas, mainly by electron impact and through metastable Ar* (Penning) collisions, respectively, observed differences are primarily due to their vastly different mean free path lengths. This affects not only possible recombination reactions, but also energy flux to the surface. The relationship between energy flux, $E_{\mathrm{i}} \cdot \Gamma_{\mathrm{i}}$, the flux of film-forming particles, $\Gamma_{\mathrm{p}}$, and their sticking probability, $s$, defines the deposited energy (in [eV]) during film growth:

$$
E_{d}=E_{i} \frac{\Gamma_{i}}{s \Gamma_{p}}
$$
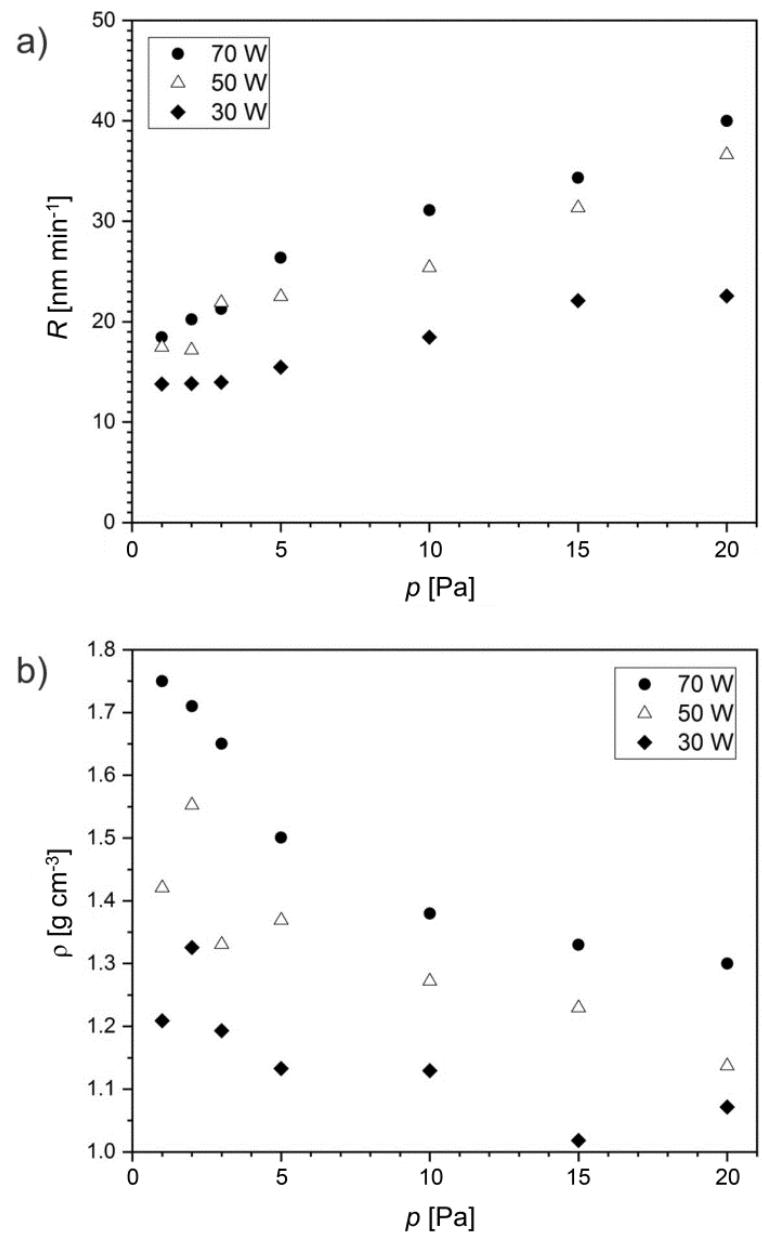

Fig. 9 Plots of deposition rate, $R(a)$; and film density, $\rho(b)$ versus pressure, $p$, for the case of $\mathrm{C}_{2} \mathrm{H}_{4}$ plasma. Monomer flow rate, $F_{\mathrm{m}}$, was fixed at $16 \mathrm{sccm}$, while power input, $W$, was varied.

An increase in $E_{\mathrm{d}}$ results in a transition from soft, polymer-like to hard, diamond-like a-C:H coatings. ${ }^{69}$ Different hydrocarbon precursors $\left(\mathrm{C}_{2} \mathrm{H}_{2}, \mathrm{C}_{2} \mathrm{H}_{4}, \mathrm{CH}_{4}\right.$, those examined here) have been reported to differently affect film properties, for example hardness of a-C: $\mathrm{H}$; however, $\mathrm{C}_{2} \mathrm{H}_{2}$ and $\mathrm{C}_{2} \mathrm{H}_{4}$ were found to yield similar results, depending on the deposited energy. 4,69

Regarding the present work with $\mathrm{LP} \mathrm{C}_{2} \mathrm{H}_{4}$ plasma, by way of example, we varied $p$ in the range $1 \leq p \leq 20 \mathrm{~Pa}$, while maintaining $F_{\mathrm{m}}$ fixed at $16 \mathrm{sccm}$ and $W$ at $30 \mathrm{~W}, 50 \mathrm{~W}$ and $70 \mathrm{~W}$, respectively (Fig. 9).

Thereby, the energy uptake by $\mathrm{C}_{2} \mathrm{H}_{4}$ molecules, $E_{\mathrm{pl}}$, in the gas phase was kept constant for the respective power inputs, but surface processes differed by varying energy flux and deposition rate, $R$. The latter was found to increase with rising $p$ (Fig. 9a), although the same flux of film-forming species, governed mainly by $E_{\mathrm{pl}}$, can be expected. However, similarly as when varying $F_{\mathrm{m}}$ values, residence times at the surface $\left(\propto p / F_{m}\right)$ are affected, which results in less re-emission of active precursor species with increasing $p$, thus higher $s$ values. ${ }^{55}$

When $p$ is lowered, mainly the ion energy, $E_{\mathrm{i}}$, increases due to less collision losses in the plasma sheath; the flux ratio $\Gamma_{\mathrm{i}} /\left(s \cdot \Gamma_{\mathrm{p}}\right)$ is less affected by variation of $p$, because ion flux $\Gamma_{\mathrm{i}}\left(\propto n_{\mathrm{e}}\right)$ was found to change in a similar manner $s \cdot \Gamma_{\mathrm{p}}(\propto R)$, as can be seen in 
Fig. 1 and Fig. 9. The reduced value of $E_{\mathrm{i}}$ at higher $p$ led to the deposition of fast-growing, rather polymer-like films with densities in the range between $1.0<\rho<1.4 \mathrm{~g} / \mathrm{cm}^{3}$ (Fig. $9 \mathrm{~b}$ ), comparable to values obtained in AP plasma. ${ }^{70}$ When lowering $p, \rho$ was found to increase and hard, diamond-like coatings could be deposited when a sufficiently high energy input was used (e.g. 70 W with $F_{\mathrm{m}}=16 \mathrm{sccm}$ of $\mathrm{C}_{2} \mathrm{H}_{4}$ ). A similar increase in $\rho$ with rising ion energy was also reported for $L P \mathrm{C}_{2} \mathrm{H}_{2}$ and $\mathrm{CH}_{4}$ plasma. ${ }^{4,71}$ One can conclude that under LP conditions, surface processes such as densification and cross-linking dominate film characteristics, while gas phase processes were found to be invariable when progressing from LP to AP.

\section{Conclusions}

The comparison of different hydrocarbon precursor gases used for plasma polymerization at low pressure (LP, CCP, RF) and atmospheric pressure (AP, DBD, a.c.) has revealed threshold energies for fundamental processes in the gas phase that agree quite well among the two. Hence, energy transfer by electron impact (at LP) and mainly via energetic $\mathrm{Ar}^{*}$ and $\mathrm{Ar}^{+}$species (Penning transfer, at AP) appears to proceed in similar ways for initiating non-thermal plasma-chemical reaction channels characterized by a particular activation barrier. However, each of the three hydrocarbons, $\mathrm{CH}_{4}, \mathrm{C}_{2} \mathrm{H}_{2}$, and $\mathrm{C}_{2} \mathrm{H}_{4}$ have revealed distinct characteristics in their plasma-chemical reaction pathways; these are mainly related to types of activation channels, namely hydrogen abstraction or $\mathrm{C}-\mathrm{C}$ bond dissociation, depending on respective threshold energies reported in the literature.

At AP conditions, recombination reactions and oligomerization (in the case of unsaturated precursors) in the gas phase were found to be important by allowing high radical density and high collision frequency; it transpires that different recombination rates need to be considered for the various reactive species involved. Recombination/oligomerization had the effect to reduce the overall numbers of different hydrocarbon species in the gas phase; it was manifested by lower-than-expected values of the energy conversion efficiency (ECE), mainly in the intermediate energy input range; $\mathrm{CH}_{4} \mathrm{AP}$ plasma showed a particularly strong contribution from recombination reactions, in the form of a very pronounced dip in ECE. Hence, for the case of $\mathrm{CH}_{4}$ recombination and subsequent chemical reactions in the plasma at AP alter the reaction pathway compared to the LP counterpart. For the case of $\mathrm{C}_{2} \mathrm{H}_{2}$ AP plasma, the observed dip in ECE due to recombination was found to be small, because predominant formation of $\mathrm{C}_{2} \mathrm{H} \cdot$ radicals maintained roughly constant the overall number of hydrocarbon species in the discharge zone. As a consequence, a near-linear increase in $E_{\mathrm{m}}$ was observed up to the apparent activation energy threshold. With increasing energy input, more reactive radicals were produced that readily led to deposition; this reduction through surface losses in turn led to a sharp drop in $E_{\mathrm{m}}$ above the activation energy. Finally, for $\mathrm{C}_{2} \mathrm{H}_{4}$, different reaction pathways and increasing importance of recombination reactions could be inferred. Turning to the LP cases, a linear increase in deposited mass, proportional to the flux of film-forming species produced in the gas phase, was observed for all three hydrocarbon precursors up to a certain threshold energy, followed by Arrhenius-like behavior that bore witness to reactions with an energy barrier. Excluding thermal effects in the gas phase, the maximum attainable $E C E$ is thus limited to $\sim 37 \%$. At sufficiently low $p$, increasing energy deposited during film growth can induce surface processes which dominate film properties, for example ones that lead to dense, hard a-C:H deposits.

\section{Conflicts of interest}

There are no conflicts to declare.

\section{Acknowledgements}

The Montreal team is grateful for financial support from the Natural Sciences and Engineering Research Council of Canada (NSERC) and from the Fonds de recherche du Québec - Nature et technologies (FRQNT) via Plasma Québec. We thank Dr. Hervé Gagnon for valuable discussions and assistance, and Yves Leblanc for skilled technical work. The St.Gallen team thanks Thomas Niessen and Urs Schütz for their skillful technical assistance.

\section{References}

1 C. P. Ho and H. Yasuda, J. Biomed. Mater. Res., 1988, 22, 919937.

2 J. Robertson, Diamond Relat. Mater., 1994, 3, 361-368.

3 T. Schwarz-Selinger, A. von Keudell and W. Jacob, J. Appl. Phys., 1999, 86, 3988-3996.

4 S. Peter, K. Graupner, D. Grambole and F. Richter, J. Appl. Phys. 2007, 102, 053304.

5 R. Pothiraja, N. K. Bibinov and P. Awakowicz, in Chemical Kinetics, ed. V. Patel, InTech, 2012, Ch. 11, 227-252.

6 A. Shirakura, M. Nakaya, Y. Koga, H. Kodama, T. Hasebe and T. Suzuki, Thin Solid Films, 2006, 494, 84-91.

7 R. Hauert, K. Thorwarth and G. Thorwarth, Surf. Coat. Technol., 2013, 233, 119-130.

8 H. Moriguchi, H. Ohara and M. Tsujioka, SEl Technical Review, 2016, 82, 52-58.

9 M. Amberg, M. Vandenbossche and D. Hegemann, Surf. Coat. Technol., 2018, 336, 29-33.

10 S. Paulussen, R. Rego, O. Goossens, D. Vangeneugden and K. Rose, J. Phys. D: Appl. Phys., 2005, 38, 568-575.

11 P. Heyse, R. Dams, S. Paulussen, K. Houthoofd, K. Janssen, P. A. Jacobs and B. F. Sels, Plasma Process. Polym., 2007, 4, 145157.

12 F. Fanelli, A. M. Mastrangelo and F. Fracassi, Langmuir, 2014, 30, 857-865.

13 T. H. Chandrashekaraiah, R. Bogdanowicz, E. Rühl, V. Danilov, J. Meichsner, S. Thierbach and R. Hippler, Materials, 2016, 9, 594.

14 S. Pedram, H. R. Mortaheb and F. Arefi-Khonsari, Plasma Process Polym., 2018, 15, e1800016.

15 J. C. Ruiz, P. L. Girard-Lauriault, F. Truica-Marasescu and M. R. Wertheimer, Radiat. Phys. Chem., 2010, 79, 310-314.

16 J. C. Ruiz, A. St-Georges-Robillard, C. Theresy, S. Lerouge and M. R. Wertheimer, Plasma Process. Polym., 2010, 7, 737-753.

17 S. Babaei and P. L. Girard-Lauriault, Plasma Chem. Plasma Process., 2016, 36, 651-666. 
18 M. Vandenbossche and D. Hegemann, Current Opin. Solid State Mater. Sci., 2018, 22, 26-38.

19 D. Merche, N. Vandencasteele and F. Reniers, Thin Solid Films, 2012, 520, 4219-4236.

20 M. Laurent, E. Desjardins, M. Meichelboeck, N. Naude, L. Stafford, N. Gherardi and G. Laroche, J. Phys. D: Appl. Phys., 2017, 50, 475205 .

21 R. Brandenburg, Plasma Sources Sci. Technol., 2017, 26, 053001.

22 C. P. Klages, A. K. Czerny, J. Philipp, M. M. Becker and D. Loffhagen, Plasma Process. Polym., 2017, 14, e1700081.

23 J. R. Toth, X. Shen, D. J. Lacks and R. M. Sankaran, Ind. Eng. Chem. Res., 2018, 57, 6048-6056.

24 D. Hegemann, M. M. Hossain, E. Körner and D. J. Balazs, Plasma Process. Polym., 2007, 4, 229-238.

25 J. Kim, D. B. Go and J. C. Hicks, Phys. Chem. Chem. Phys., 2017, 19, 13010-13021.

26 B. Nisol, H. Gagnon, S. Lerouge, S. and M. R. Wertheimer, Plasma Process. Polym., 2016, 13, 366-374.

27 D. Hegemann, B. Nisol, S. Watson and M. R. Wertheimer, Plasma Process. Polym., 2016, 13, 834-842.

28 D. Hegemann, B. Nisol, S. Watson and M. R. Wertheimer, Plasma Chem. Plasma Process., 2017, 37, 257-271.

29 D. Hegemann, in Comprehensive Materials Processing, ed. D. Cameron, Elsevier, Oxford, 2014, Vol. 4, 201-228.

30 D. Hegemann, M. Michlíček, N. E. Blanchard, U. Schütz, D. Lohmann, M. Vandenbossche, L. Zajíčková and M. Drábik, Plasma Process. Polym., 2016, 13, 279-286.

31 T. Minea, D. C. M. van den Bekerom, F. J. J. Peeters, E. Zoethout, M. F. Graswinckel, M. C. M. van de Sanden, T. Cents, L. Lefferts and G. J. van Rooij, Plasma Process. Polym., 2018, 15, e1800087.

32 J. Friedrich, Plasma Process. Polym., 2011, 8, 783-802.

33 W. Wang, A. Berthelot, Q. Zhang and A. Bogaerts, J. Phys. D: Appl. Phys., 2018, 51, 204003.

34 N. Fox-Lyon, G. S. Oehrlein and V. Godyak, J. Vac. Sci. Technol., 2014, 32, 030601.

35 F. Massines, N. Gherardi, N. Naude and P. Segur, Eur. Phys. J. Appl. Phys., 2009, 47, 22805.

36 I. A. Shkurenkova, Y. A. Mankelevich and T. V. Rakhimova, Eur. Phys. J. D, 2011, 61, 95-105.

37 S. Guimond, U. Schütz, B. Hanselmann, E. Körner and D. Hegemann, Surf. Coat. Technol., 2011, 205, S447-S450.

38 S. Watson, B. Nisol, S. Lerouge and M. R. Wertheimer, Langmuir, 2015, 31, 10125-10129.

39 B. Nisol, S. Watson, S. Lerouge and M. R. Wertheimer, Plasma Process. Polym., 2016, 13, 557-564.

40 M. Archambault-Caron, H. Gagnon, B. Nisol, K. Piyakis and M. R. Wertheimer, Plasma Sources Sci. Technol., 2015, 24, 045004.

41 D. Hegemann, J. Phys. D: Appl. Phys., 2013, 46, 205204.

42 K. M. Ervin, S. Gronert, S. E. Barlow, M. K. Gilles, A. G. Harrison, V. M. Bierbaum, C. H. DePuy, W. C. Lineberger and G. B. Ellison, J. Am. Chem. Soc., 1990, 112, 5750-5759.

43 Y. H. Cheng, Y. P. Wu, J. G. Chen, X. L. Qiao, C. S. Xie, B. K. Tay, S. P. Lau and X. Shi, Surf. Coat. Technol., 2000, 135, 27-33.

44 R. K. Janev and D. Reiter, Phys. Plasmas, 2004, 11, 780-829.

45 G. Le Dû, N. Celini, F. Bergaya and F. Poncin-Epaillard, Surf. Coat. Technol., 2007, 201, 5815-5821.

46 J. W. A. M. Gielen, W. M. M. Kessels, M. C. M. van de Sanden and D. C. Schram, J. Appl. Phys., 1997, 82, 2643-2654.

47 M. Bauer, T. Schwarz-Selinger, W. Jacob and A. von Keudell, J. Appl. Phys., 2005, 98, 073302.

48 N. E. Blanchard, B. Hanselmann, J. Drosten, M. Heuberger and D. Hegemann, Plasma Process. Polym., 2015, 12, 32-41.

49 J. K. Lefkowitz, M. Uddi, B. C. Windom, G. Lou and Y. Ju, Proc. Combust. Inst., 2015, 35, 3505-3512.
50 M. Bergmann, L. Ledernez, G. Dame, S. Lickert, F. Widmer, Y. Gier and G. Urban, Plasma Process. Polym., 2013, 10, 970977.

51 C. De Bie, B. Verheyde, T. Martens, J. van Dijk, S. Paulussen and A. Bogaerts, Plasma Process. Polym., 2011, 8, 1033-1058.

52 R. Snoeckx, Y. X. Zeng, X. Tu and A. Bogaerts, RSC Adv., 2015, 5, 29799-29808.

53 D. Reiter and R. K. Janev, Contrib. Plasma Phys., 2010, 50, 986-1013.

54 T. Nozaki and K. Okazaki, Catalysis Today, 2013, 211, 29-38.

55 A. Burke, G. Braeckelmann, D. Manger, E. Eisenbraun, A. E. Kaloyeros, J. P. McVittie, J. Han, D. Bang, J. F. Loan and J. J. Sullivan, J. Appl. Phys., 1997, 82, 4651-4660.

56 J. Sun and Q. Chen, J. Energy Chem., 2019, 39, 188-197.

57 K. Tachibana, M. Nishida, H. Harima and Y. Urano, J. Phys. D: Appl. Phys., 1984, 17, 1727-1742.

58 H. E. Wagner, in Low Temperature Plasma Physics, eds. R. Hippler, S. Pfau, M. Schmidt and K. H. Schoenbach, Wiley-VCH, Berlin, 2001, Ch. 12, 305-330.

59 X. Tao, M. Bai, X. Li, H. Long, S. Shang, Y. Yin and X. Dai, Prog Energy Combust. Sci., 2011, 37, 113-124.

60 N. Bundaleska, D. Tsyganov, A. Dias, E. Felizardo, J. Henriques, F. M. Dias, M. Abrashev, J. Kissovski and E. Tatarova, Phys. Chem. Chem. Phys., 2018, 20, 13810.

61 X. Zhang and M. S. Cha, Proc. Combust. Inst., 2015, 35, 34473454.

62 S. Saboohi, H. J. Griesser, B. R. Coad, R. D. Short and A. Michelmore, Phys. Chem. Chem. Phys., 2018, 20, 7033-7042.

63 H. Toyoda, H. Kojima and H. Sugai, Appl. Phys. Lett., 1989, 54, 1507-1509.

64 H. Zheng and Q. Liu, Math. Probl. Eng., 2014, 2014, 938618.

65 S. Naito, M. Ikeda, N. Ito, T. Hattori and T. Goto, Jap. J. Appl. Phys., 1993, 32, 5721-5725.

66 K. Behringer, Plasma Phys. Control. Fusion, 1991, 33, 9971028.

67 J. F. Zhang, X. C. Bian, Q. Chen, F. P. Liu and Z. W. Liu, Chin. Phys. Lett., 2009, 26, 035203.

68 E. Desjardins, M. Laurent, A. Durocher-Jean, G. Laroche, N. Gherardi, N. Naudé and L. Stafford, Plasma Sources Sci. Technol., 2018, 27, 015015.

69 R. Kleber, M. Weiler, A. Krüger, S. Sattel, G. Kunz, K. Jung and H. Ehrhardt, Diamond Relat. Mater., 1993, 2, 246-250.

70 S. P. Bugaev, A. D. Korotaev, K. V. Oskomov and N. S. Sochugov, Surf. Coat. Technol., 1997, 96, 123-128.

71 B. K. Kim and T. A. Grotjohn, Diamond Relat. Mater., 2000, 9, $37-47$ 